\title{
GEOLOGIA E MINERALOGIA DO KIMBERLITO GROTA DO CEDRO (COROMANDEL, MG)
}

\author{
Kerley Wanderson Andrade ${ }^{1}$, Mario Luiz de Sá Carneiro Chaves ${ }^{2}$
}

\begin{abstract}
RESUMO: Centenas de intrusões kimberlíticas e de rochas relacionadas são conhecidas na região de Coromandel (MG), abrangendo a designada "Província Diamantífera Alto Paranaíba", embora o conhecimento sobre essas rochas ainda seja escasso. Entre essas intrusões, ressalta-se o kimberlito Grota do Cedro, que afora na drenagem homônima ao sul de Coromandel (MG), encaixada em micaxistos do Grupo Araxá (Neoproterozóico). O corpo apresenta forma superficial aproximadamente elíptica com cerca de 350 × $300 \mathrm{~m}$ de eixos; sua composição química é similar a de outras da província e a química mineral do Cr-piropo revelou uma forte concentração nos campos "G9" e "G5". Esses campos mineraloquímicos, em geral caracterizam intrusões pobres ou mesmo inférteis em diamantes.
\end{abstract}

Palavras-chave: Kimberlito, Coromandel, Diamantes.

\begin{abstract}
GEOLOGY AND MINERALOGY OF THE GROTA DO CEDRO KIMBERLITE (COROMANDEL, MG). Hundreds of kimberlite intrusions and related rocks are known in the Coromandel region (MG), in the "Alto Paranaiba Diamondiferous Province", although the knowledge of these rocks is still scarce. Among these intrusions, it emphasizes the Grota do Cedro kimberlite, which outcrops in the drainage of same name at south of Coromandel (MG), hosted in micaschists of the Araxá Group (Neoproterozoic). The body has a roughly elliptical surface shape with 350 and $300 \mathrm{~m}$ axis; its chemical composition is similar to others of the province, and mineral chemistry of Cr-pyrope shows a strong concentration in the "G9" and "G5" fields. These chemical fields generally characterize diamond-poor or infertile intrusions.
\end{abstract}

Keywords: Kimberlite, Coromandel, Diamonds.

\section{INTRODUÇÃO}

O kimberlito Grota do Cedro, também conhecido como Douradinho-8, foi descoberto em 1970 pela SOPEMI-BRGM (órgão estatal francês de mineração), na sequência de diversas outras encontradas na mesma região. A SOPEMI foi posteriormente encampada pelo grupo sul-africano De Beers (1975), e ambas pesquisaram somente nos arredores de Coromandel e municípios circunvizinhos cerca de 100 intrusões da mesma natureza ou geneticamente relacionadas, a grande maioria sub-aflorantes. Entretanto, nunca foi confirmada uma ligação entre tais intrusões e a mineralização de diamantes presente em inúmeros córregos e rios dessa região, designada "Província Diamantífera Alto Paranaíba" (Chaves et al., 2006).

O presente estudo constitui uma extensão de outro anterior, que efetuou o mapeamento geológico em semidetalhe (1:40.000) da área onde o kimberlito encontrase inserido (Andrade \& Chaves, 2009). Os objetivos principais consistem em detalhar a anatomia da intrusão e a relação com as encaixantes, bem como apresentar dados inéditos sobre a geoquímica da rocha, dos xenólitos mantélicos presentes, e a química mineral de granadas extraídas do corpo. O Córrego Grota do Cedro, onde o corpo aflora, é um dos afluentes das cabeceiras do Rio Douradinho, famoso pelo encontro periódico de grandes diamantes (Barbosa, 1991), e cujos microdiamantes foram estudados em detalhe anteriormente por Chaves et al. (2005).

\section{LOCALIZAÇÃO E ACESSO}

O corpo estudado localiza-se ao sul de Coromandel, município situado no extremo sudoeste de Minas Gerais e fronteiriço com Goiás, a leste da "Chapada do Testa" (UTM-GPS 271768 / 7940277, zona 23). O acesso desde a cidade é feito por vias não pavimentadas, inicialmente em direção a Santa Rosa dos Dourados e depois no rumo da Fazenda Arcos. Coromandel dista cerca de $480 \mathrm{~km}$ de Belo Horizonte, sendo acessado pelas BR-262 até o trevo de Ibiá, de onde se toma a MG-230 em direção a Patrocínio, e depois um curto trecho de cerca de $10 \mathrm{~km}$ na BR-365. A partir desta estrada, se alcança a cidade através da rodovia MG-188 (Figura 1). 


\section{SÍNTESE GEOLÓGICA REGIONAL}

Andrade (2008) e Andrade \& Chaves (2009) apresentaram o mapa geológico da área, na escala 1:40.000, abrangendo um polígono com cerca de 250 $\mathrm{km}^{2}$ localizado ao sul de Coromandel (Figura 1). Entre os principais trabalhos de âmbito regional, ressaltam-se os de Barbosa et al. (1970), a 1:250.000, e de Heineck et al. (2003), ao milionésimo.

As unidades mais antigas, neoproterozóicas, incluem os grupos Canastra, Araxá e Ibiá. O Grupo Canastra, na base, em geral é atribuído ao Mesoproterozóico (e.g., Heineck et al., 2003) embora dados recentes revelem sua idade neoproterozóica (Pimentel et al., 2011), ocorrendo a nordeste da região, e constituído principalmente por quartzitos com intercalações locais de filitos sericíticos e quartzo-micaxistos. Essa sequência metassedimentar é sobreposta por contato tectônico pelo Grupo Ibiá, que ocorre na faixa central da área com predomínio de filitos calcíferos esverdeados, em geral fortemente intemperizados. Em contato também tectônico, o Grupo Araxá aparece no topo do pacote proterozóico, representado a sudoeste do mapa por quartzo-sericitaxistos e sericitaxistos, no qual o kimberlito Grota do Cedro aparece encaixado (Figura1, destaque).

Essas três sequências proterozóicas são cobertas discordantemente por rochas sedimentares cretácicas, as quais formam mesetas testemunhas na paisagem. Os litotipos presentes incluem conglomerados basais e arenitos, ambos com marcante contribuição vulcânica, atribuídos à Formação Capacete (Grupo Mata da
Corda). As intrusões kimberlíticas na região ocorreram mais ou menos concomitantemente à deposição do Grupo Mata da Corda (Sgarbi et al., 2001). Nas encostas a oeste do vale do Rio Douradinho, ocorrem depósitos fanglomeráticos terciários ou sub-recentes, onde é verificada a maior parte da garimpagem de diamantes (Andrade, 2008).

Em termos geotectônicos, a região encontra-se inserida na Faixa de Dobramentos Brasília, em seu setor sul, a qual se estruturou durante o ciclo orogênico Brasiliano (630-490 Ma) (Almeida, 1977; Seer, 1999; Pimentel et al., 2011). No final do Mesozóico, desenvolveu-se expressivo evento sedimentar sobre grandes extensões dos terrenos pretéritos, com a estruturação da Bacia Sanfranciscana, caracterizandose como o último ciclo geodinâmico ocorrido sobre a área cratônica (Campos \& Dardenne, 1997; Sgarbi et al., 2001). Os derrames vulcânicos, depósitos clásticos e piroclásticos, bem como intrusões ultrabásicoalcalinas tiveram aporte na bacia gerada em regime tectônico de subsidência termal, em associação direta à estruturação de um alto do embasamento conhecido como "Soerguimento do Alto Paranaíba" (Ladeira et al., 1971; Campos \& Dardenne, 1997).

\section{KIMBERLITO GROTA DO CEDRO}

\section{Expressão superficial e geologia}

O kimberlito faz contato abrupto com micaxistos do Grupo Araxá, que na área apresentam foliação
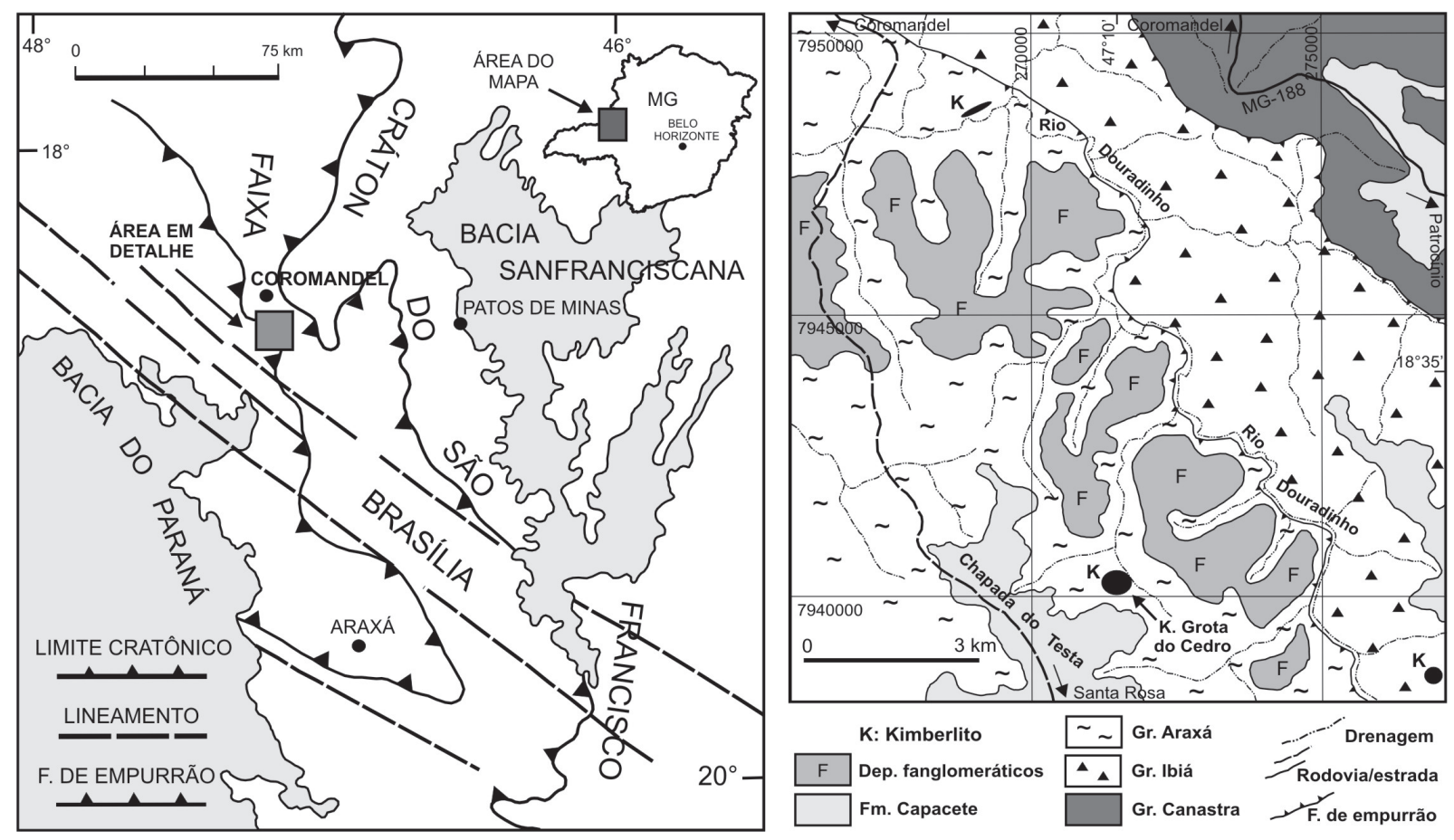

Figura 1: Localização da área estudada, na porção oeste de Estado de Minas Gerais junto à fronteira com Goiás, ressaltando seu posicionamento próximo à borda leste da Faixa de Dobramentos Brasília (à esquerda; base geológica segundo Heineck et al., 2003). À direita, em destaque a área onde se situa o kimberlito Grota do Cedro (geologia modificada de Andrade, 2008 e Andrade \& Chaves, 2009). 
homogênea com atitude em torno de $\mathrm{N} 20^{\circ} \mathrm{W} / 50^{\circ} \mathrm{SW}$. Ele aflora sobre um trecho de direção NW-SE de cerca de $30 \mathrm{~m}$ ao longo da calha encaixada do Córrego Grota do Cedro. Aparentemente é sobreposto pelas rochas cretácicas, que compõem a "Chapada do Testa", a oeste (Figura 2-A).

A partir do mapa geofísico por aeromagnetometria de semi-detalhe, obtido através de levantamento por helicóptero e cedido pela SAMSUL Mineração (Figura 2-B), foram executados perfis radiométricos expeditos com cintilômetro, para confirmação e detalhamento da expressão superficial do corpo. Tais perfis foram executados numa várzea aplainada a oeste da drenagem, visto que a leste o relevo mais acidentado indicava área o predomínio dos xistos encaixantes. Verificou-se espessura, é formado por sedimentos horizontalizados, altamente silicificados e bandados, parecendo constituir um material de preenchimento da zona de cratera da intrusão (Figura 3-D).

\section{GEOQUÍMICA DE ROCHAS}

Análises geoquímicas de rocha total do corpo, bem como de xenólitos mantélicos extraídos da mesma, foram efetuadas através de fluorescência de raios-X (elementos maiores), ICP-MS (elementos menores e traços) e IMS-95R (terras raras), nos laboratórios SGSGEOSOL (Vespasiano, MG). No estudo, realizaram-se ainda, para vias de comparação, análises sobre outros kimberlitos da mesma província, como os corpos
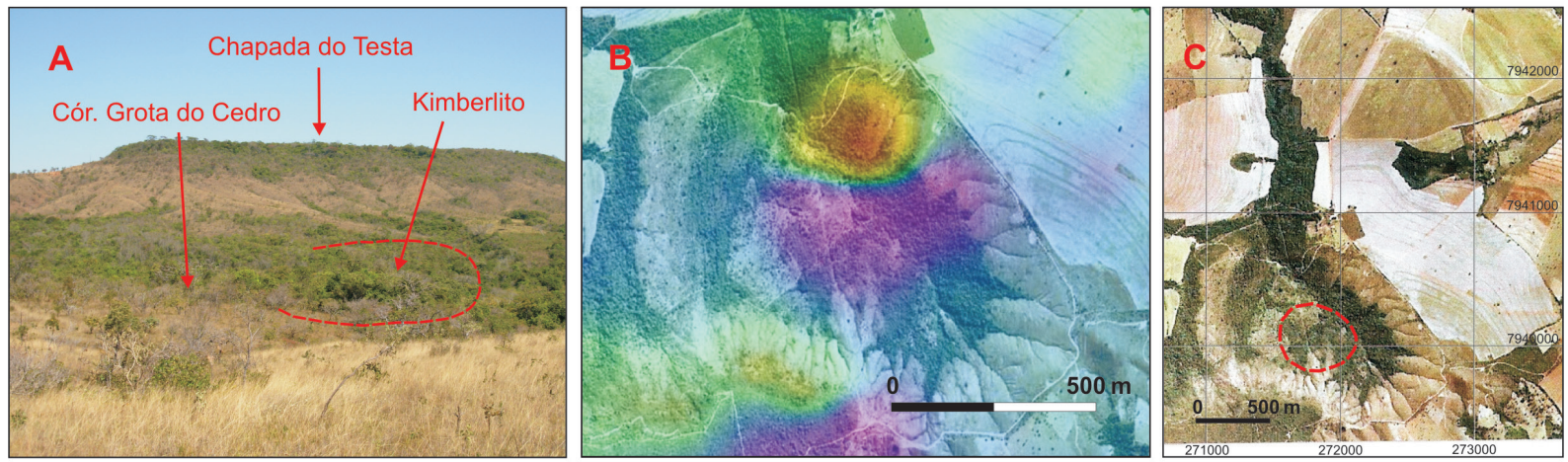

Figura 2: (A) Expressão superficial aproximada do kimberlito, aflorando entre o Córrego Grota do Cedro e a Chapada do Testa; (B) Superposição de mapa aeromagnetométrico sobre fotografia área da intrusão na mesma escala (imagem cedida pela SAMSUL Mineração; (C) Formato aproximado do corpo obtido através de levantamento de campo e perfis cintilométricos sobre aerofotografia colorida (Imagem IBGE, ortomosaico na escala original 1:35.000).

uma anomalia suave de cerca de 200-250 cps no corpo, contra valores entre 50-80 cps nos litotipos xistosos.

Na obtenção dos contatos, os dados cintilométricos foram ainda refinados utilizando-se afloramentos de xistos alterados em ravinas, bem como pela observação de miniquebras abruptas no relevo, típicas de intrusões de natureza kimberlítica. A integração das informações anteriormente relacionadas indicou a presença de um corpo de forma aproximadamente elíptica cujo eixo leste-oeste $(350 \mathrm{~m})$ é ligeiramente maior que o outro (300 m) (Figura 2-C).

Na parte aflorante do kimberlito, se observam, a partir do leito do córrego, uma brecha cinza esverdeada escura, bastante fresca e rica em macrocristais de olivina, ilmenita e xenólitos crustais de xistos Araxá (Figura 3-A). Ao microscópio observou-se que essa matriz é composta por uma agregado fino constituído de olivina, flogopita, perovskita, serpentina, calcita, barita, zircão e opacos. Concentrações anômalas de perovskita e opacos por vezes formam coroas em torno de olivinas e flogopitas alteradas. Acima, ocorre uma brecha verde mais alterada, de grãos menores e com porções de insignificante brechiação (Figura 3-B), a qual no topo apresenta uma coloração rósea, provavelmente devido a percolação de material do nível superior (Figura 3-C). Esse nível, com cerca de $5 \mathrm{~m}$ de
"Indaiá", "Limeira", "Forca" e "Abel Régis", os dois primeiros estudados também por Svisero et al. (1980). Corpos também importantes, como "Sucuri", "Pântano" e "Japecanga", foram analisados por Svisero et al. (1982), Meyer et al. (1991) e Bizzi et al. (1991), respectivamente (Tabela 1$)$.

O xenólito X-04 apresenta composição química distinta dos demais xenólitos analisados (X-01, X-02 e X-03), diferindo destes em termos de diversos óxidos e perda ao fogo. Todavia, apesar dessa divergência de padrão, os intervalos gerais são compatíveis com os valores presentes em xenólitos de outras intrusões da província (Carlson et al., 2007). Segundo esses autores, tal variação é relacionada a processos de fusão parcial dos xenólitos, comum em crátons continentais, devido suas interações com o magma kimberlítico, permitindo a depleção de certos elementos. Estes valores também são concordantes com os dados de xenólitos do kimberlito Limeira-1, $\mathrm{SiO}_{2}(\sim 40 \%), \mathrm{Al}_{2} \mathrm{O}_{3}(\sim 0,8 \%)$, $\mathrm{MnO}(\sim 0,1 \%), \mathrm{Na}_{2} \mathrm{O}(\sim 0,1 \%)$ e $\mathrm{K}_{2} \mathrm{O}(\sim 0,4 \%)$ (conforme Almeida, 2009), indicando que o padrão é recorrente a outras intrusões próximas.

As análises revelaram que o kimberlito estudado tem composição química similar à de diversos outros da mesma região, bem como de muitos a nível mundial (cf. Svisero et al., 1984 e Mitchell, 1986), ressaltando- 

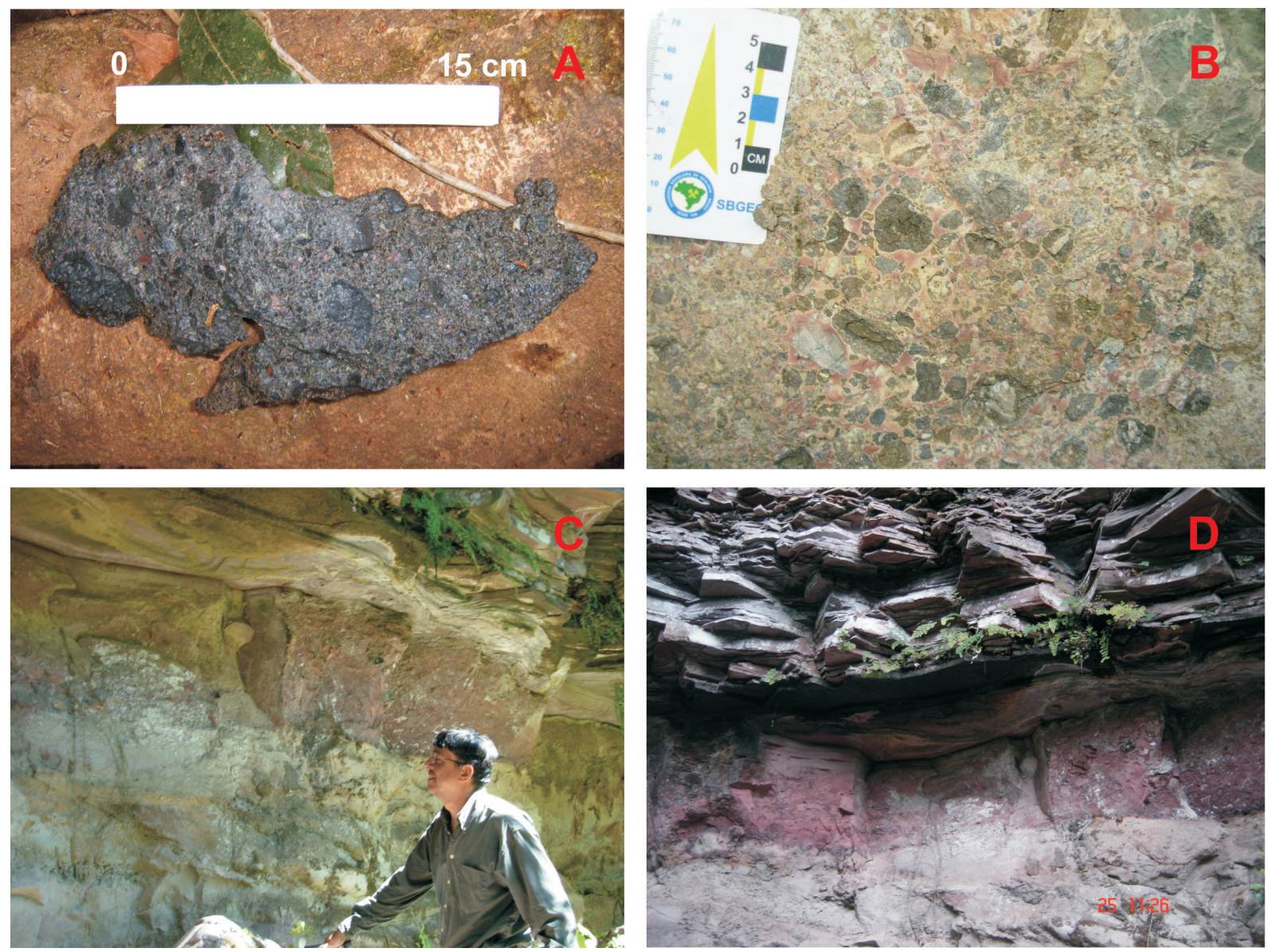

Figura 3: (A) Brecha kimberlítica aflorando no leito do Córrego Grota do Cedro; (B) Detalhe da brecha com grãos menores e porções sem brechiação, de ocorrência logo acima da brecha anterior; (C) Porção superior da exposição, onde o nível de brechas finas fica rosado, provavelmente por percolação de material vindo do nível de topo (D) constituído de sedimentos silicificados, fortemente bandados.

Tabela 1: Análises químicas por fluorescência de raios-X em amostras de rochas $(R)$ e xenólitos $(X)$ do kimberlito Grota do Cedro. São apresentados dados comparativos de outras intrusões da região: Forca (1), Indaiá (2,3), Limeira (4,5), Sucuri (6), Pântano $(7,8)$ e Japecanga (9) (dados de \% em peso; todo ferro contido como FeO). $(1,2,4,10)$ Dados adquiridos (Lab. SGS-

Geosol).; (3,5) Svisero et al. (1980); (6) Svisero et al. (1982); (7) Meyer et al. (1991); (8,9) Bizzi et al. (1991).

\begin{tabular}{c|rrrrrrrrrrrr}
$\mathrm{N}^{\circ}$ & $\mathrm{SiO}_{2}$ & $\mathrm{Al}_{2} \mathrm{O}_{3}$ & $\mathrm{MgO}$ & \multicolumn{1}{c}{$\mathrm{FeO}$} & \multicolumn{1}{c}{$\mathrm{CaO}$} & $\mathbf{M n O}$ & $\mathrm{TiO}_{2}$ & $\mathbf{N a}_{2} \mathrm{O}$ & $\mathrm{K}_{2} \mathrm{O}$ & $\mathbf{P}_{2} \mathbf{O}_{5}$ & \multicolumn{1}{c}{$\mathbf{P . F .}$} & Total \\
\hline $\mathrm{R}-01$ & 35,41 & 5,06 & 14,91 & 10,51 & 9,75 & 0,23 & 2,98 & 0,19 & 3,25 & 0,86 & 15,93 & 99,08 \\
$\mathrm{R}-02$ & 38,33 & 6,65 & 12,41 & 11,01 & 9,67 & 0,24 & 3,34 & 0,45 & 1,89 & 1,47 & 13,93 & 99,39 \\
$\mathrm{R}-03$ & 39,63 & 7,57 & 11,79 & 13,99 & 9,59 & 0.19 & 4,55 & 0,83 & 1,81 & 2,11 & 6,01 & 97,88 \\
$\mathrm{X}-01$ & 41,09 & 6,73 & 11,91 & 15,42 & 9,19 & 0,18 & 4,88 & 0,88 & 1,91 & 1,84 & 5,22 & 99,25 \\
$\mathrm{X}-02$ & 41,11 & 6,79 & 11,35 & 15,87 & 10,02 & 0,19 & 4,99 & 0,73 & 1,52 & 1,97 & 4,78 & 99,32 \\
$\mathrm{X}-03$ & 41,31 & 6,86 & 10,94 & 13,94 & 10,23 & 0,17 & 4,64 & 0,95 & 2,29 & 1,84 & 5,25 & 98,42 \\
$\mathrm{X}-04$ & 36,02 & 4,88 & 11,53 & 12,22 & 8,45 & 0,17 & 6,31 & 0,41 & 5,21 & 0,81 & 13,78 & 99,79 \\
\hline$(1)$ & 33,21 & 1,71 & 28,23 & 11,17 & 8,38 & 0,21 & 2,29 & 0,12 & 0,33 & 0,77 & 14,22 & 99,64 \\
$(2)$ & 29,50 & 2,22 & 27,70 & 11,80 & 13,10 & 0,23 & 2,55 & 0,13 & 1,04 & 2,92 & 9,41 & 100,60 \\
$(3)$ & 26,95 & 4,56 & 28,09 & 9,64 & 13,77 & nd & nd & 0,15 & 1,01 & nd & 10,49 & 94,66 \\
$(4)$ & 30,30 & 1,86 & 30,10 & 11,50 & 10,80 & 0,21 & 2,39 & $<0,10$ & 0,95 & 2,42 & 9,46 & 99,99 \\
$(5)$ & 29,31 & 3,59 & 30,33 & 9,90 & 11,40 & nd & nd & 0,09 & 0,91 & nd & 10,37 & 95,90 \\
$(6)$ & 38,28 & 7,85 & 20,10 & 13,93 & 12,08 & nd & nd & 0,68 & 1,75 & nd & 5,16 & 99,83 \\
$(7)$ & 31,73 & 4,14 & 20,13 & 13,70 & 10,52 & 0,30 & 6,40 & 0,26 & 1,98 & 0,63 & nd & 89,79 \\
$(8)$ & 32,27 & 2,49 & 24,09 & 14,06 & 10,95 & 0,24 & 4,78 & 0,10 & 2,42 & 0,93 & 6,63 & 98,96 \\
$(9)$ & 33,73 & 0,75 & 31,55 & 13,34 & 2,62 & 0,19 & 2,55 & 0,02 & 0,20 & 0,19 & 14,74 & 99,88 \\
$(10)$ & 44,20 & 7,05 & 12,7 & 10,05 & 7,70 & 0,16 & 4,26 & 1,76 & 3,58 & 0,61 & 6,38 & 99,02
\end{tabular}


se sua distinção com os pipes de Japecanga e Pântano, considerados mica-peridotitos por Bizzi et al. (1991), e com a intrusão Abel Régis, de Carmo do Paranaíba, que parece ter uma composição transicional entre kimberlitos e lamproítos (Chaves et al., 2009).

\section{QUÍMICA MINERAL}

Análises mineraloquímicas com microssonda eletrônica, realizadas no LMA do Departamento de Física da UFMG, foram realizadas sobre 20 granadas extraídas do corpo (Tabela 2, foram excluídas as análises com "fechamento" indesejado). Essas granadas, todas do tipo piropo, revelaram em geral expressivas quantidades de cromo. geral variam entre 87-86 Ma no kimberlito Poço Verde (Davis, 1977), e 83 Ma no kimberlito Santa Rosa-4 (Pereira, 2007).

Os kimberlitos da região de Coromandel possuem fortes semelhanças petrográfica, geoquímica e mineralógica com outras intrusões da mesma natureza nos crátons sul-africano, oeste-africano e siberiano (Svisero et al., 1984). Entretanto, o posicionamento geotectônico desses corpos é peculiar, uma vez que eles se encontram na Faixa de Dobramentos Brasília. A esse respeito, Pires (1984) supôs um limite cratônico mais ao sul, e assim o contorno estabelecido para a zona dobrada seria diferente, indicando que na região a faixa de dobramentos teria sido acrescida ao cráton durante

Tabela 2: Composição química de amostras representativas de Cr-piropo do kimberlito Grota do Cedro. Análises no LMA, Dep. De Física da UFMG (dados de \% em peso; todo ferro contido como $\mathrm{FeO}$ ).

\begin{tabular}{c|cccccccccr} 
No Amostra & $\mathbf{S i O}_{2}$ & $\mathbf{A l}_{2} \mathbf{O}_{3}$ & $\mathbf{M g O}$ & $\mathbf{F e O}$ & $\mathbf{C a O}$ & $\mathbf{C r}_{2} \mathbf{O}_{3}$ & $\mathbf{M n O}$ & $\mathbf{T i O}_{2}$ & $\mathbf{N a}_{2} \mathbf{O}$ & TOTAL \\
\hline GC-P-01 & 41,49 & 17,41 & 17,64 & 7,69 & 7,08 & 8,72 & 0,51 & 0,28 & 0,03 & 100,57 \\
GC-P-02 & 42,19 & 21,08 & 18,37 & 8,69 & 5,65 & 3,87 & 0,46 & 0,19 & 0,02 & 100,52 \\
GC-P-03 & 41,41 & 22,61 & 20,33 & 8,25 & 4,28 & 2,18 & 0,42 & 0,32 & 0,05 & 99,85 \\
GC-P-05 & 41,11 & 21,91 & 19,22 & 9,28 & 4,53 & 3.11 & 0,47 & 0,17 & 0,04 & 99,85 \\
GC-P-06 & 40,35 & 20,06 & 17,97 & 8,38 & 6,47 & 5,71 & 0,49 & 0,07 & 0,02 & 99,52 \\
GC-P-07 & 40,99 & 19,92 & 19,31 & 7,73 & 5,31 & 5,74 & 0,41 & 0,25 & 0,03 & 99,69 \\
GC-P-09 & 41,36 & 21,87 & 19,46 & 8,98 & 4,47 & 3,29 & 0,35 & 0,16 & 0,04 & 99,98 \\
GC-P-10 & 40,68 & 19,86 & 17,71 & 8,31 & 6,82 & 5,88 & 0,42 & 0,02 & 0,01 & 99,71 \\
GC-P-11 & 41,81 & 20,48 & 19,58 & 7,87 & 5,08 & 4,59 & 0,39 & 0,33 & 0,05 & 100,18 \\
GC-P-12 & 40,61 & 19,91 & 18,33 & 8,45 & 5,96 & 5,49 & 0,43 & 0,15 & 0,01 & 99,34 \\
GC-P-14 & 40,62 & 21,52 & 18,77 & 8,34 & 6,51 & 4,02 & 0,39 & 0,09 & 0,03 & 100,29 \\
GC-P-15 & 41,81 & 21,94 & 19,16 & 9,03 & 4,53 & 3,08 & 0,43 & 0,15 & 0,04 & 100,17 \\
GC-P-16 & 42,25 & 21,95 & 19,75 & 8,03 & 4,55 & 3,14 & 0,38 & 0,01 & 0,02 & 100,08 \\
GC-P-17 & 41,04 & 20,07 & 17,57 & 8,21 & 6,75 & 5,63 & 0,44 & 0,03 & 0,01 & 99,75 \\
GC-P-18 & 41,29 & 21,25 & 18,69 & 8,45 & 5,46 & 4,03 & 0,44 & 0,09 & 0,03 & 99,73 \\
GC-P-19 & 41,24 & 21,84 & 18,61 & 8,53 & 5,42 & 3,29 & 0,41 & 0,11 & 0,03 & 99,48 \\
GC-P-20 & 41,07 & 20,06 & 17,15 & 8,49 & 6,94 & 5,74 & 0,51 & 0,04 & 0,01 & 100,01
\end{tabular}

A figura 4 mostra os piropos analisados, conforme plotagem no diagrama $\mathrm{CaO} \times \mathrm{Cr}_{2} \mathrm{O}_{3}$ de Grütter et al. (2004). Os dados ressaltam a forte concentração nos campos mineraloquímicos "G9" e "G5", os quais, a nível mundial, em geral caracterizam intrusões pobres ou inférteis em diamantes.

\section{CONSIDERAÇÕES FINAIS}

O kimberlito Grota do Cedro compõe um cluster junto com dezenas de outros na mesma região (Figura 5), a grande maioria ainda carente de estudos mais detalhados, tendo em vista que as pesquisas a respeito ficaram sempre em sigilo, de posse dos detentores dos respectivos direitos minerários. Comparado a outros kimberlitos da mesma região, ele apresenta fortes semelhanças de cor e texturais com o kimberlito Vargem-1, que aflora a leste, e também semelhanças químicas e mineralógicas com os outros poucos já descritos (cf. tabela 1). As idades dessas intrusões em

o Ciclo Brasiliano. De modo semelhante, Carvalho (1997) demonstrou em estudos geotermobarométricos de xenólitos de diversas intrusões que o manto na região é subcratônico, possuindo condições de ser fértil para diamantes.

É provável que a Formação Capacete seja de idade imediatamente posterior ao período principal de ocorrência das intrusões, tendo em vista a forte contribuição de minerais kimberlíticos nos conglomerados e arenitos cineríticos posicionados na base da mesma. De tal modo, diversos autores têm destacado uma associação dos diamantes de Coromandel com os eventos magmáticos citados e/ ou a seus produtos clásticos derivados (e.g., Barbosa et al., 1970; Svisero et al., 1984; Leonardos et al., 1995; Read et al., 2004). O motivo de ainda não terem sido encontrados kimberlitos férteis na região é controvérsico. Chaves (1991) atribui tal fato ao predomínio de zonas de raiz nessas intrusões, onde em geral a mineralização é rarefeita. Outra linha de idéias 


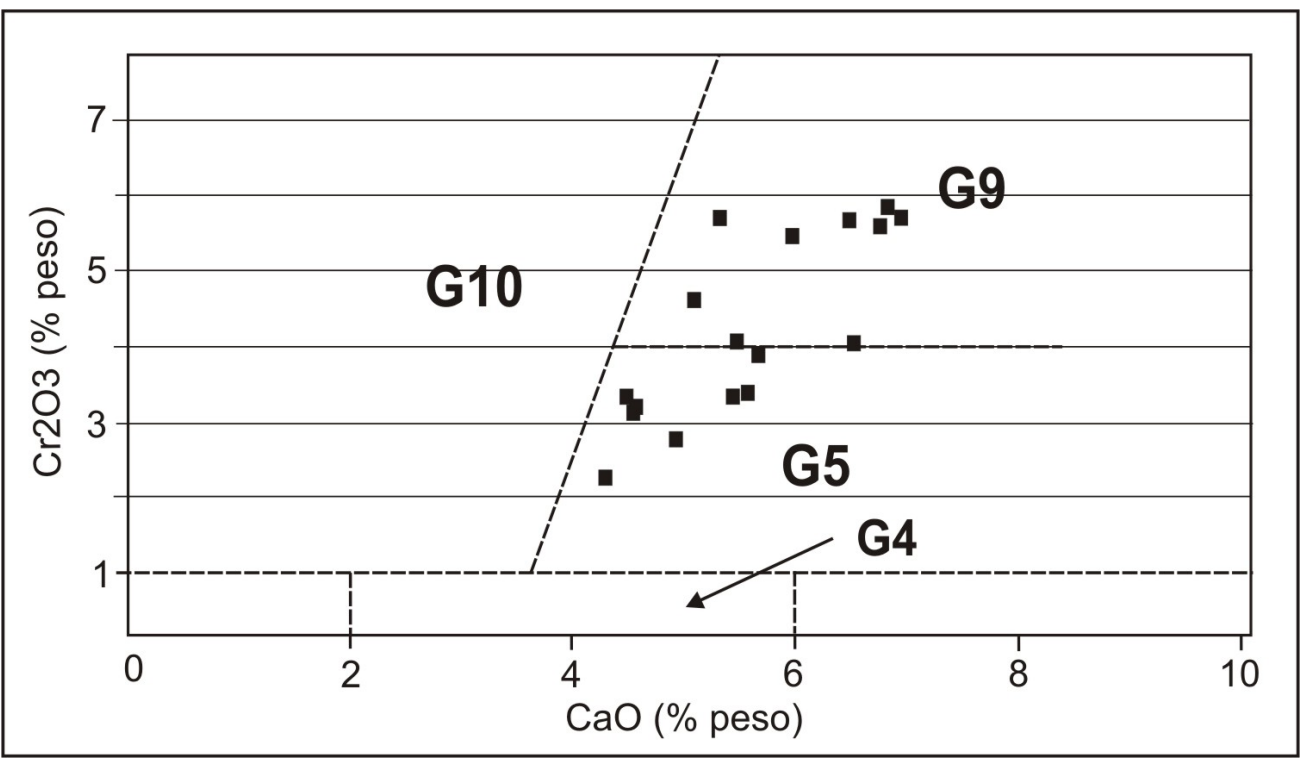

Figura 4: Diagrama CaO versus $\mathrm{Cr}_{2} \mathrm{O}_{3}$ em Cr-piropos do kimberlito Grota do Cedro enfatizando os campos mineraloquímicos pertinentes a granadas kimberliticas conforme Grütter et al. (2004).

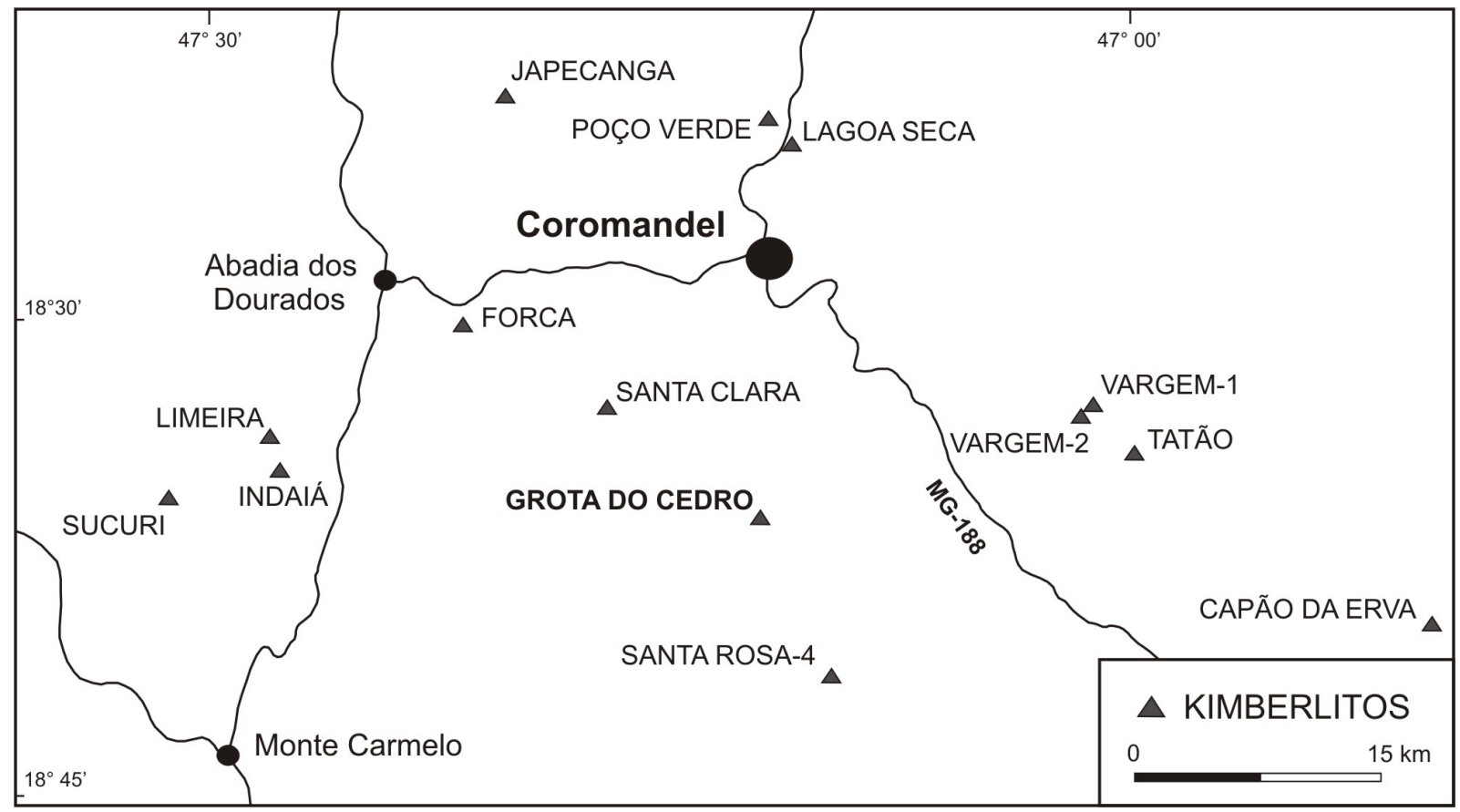

Figura 5: Principais intrusões kimberlíticas da região de Coromandel $(M G)$ destacando ao centro a intrusão Grota do Cedro.

acredita que as pesquisas realizadas na maioria dos casos foi insuficiente ou até inadequada para definição dos reais teores presentes (Chaves et al., 2008, 2009).

\section{AGRADECIMENTOS}

Os autores expressam seus agradecimentos à SAMSUL Mineração, então permissionária dos direitos de pesquisa da área estudada, pelas informações prestadas. O segundo (MLSCC), agradece ainda ao CNPq pela concessão de Bolsa de Produtividade em Pesquisa.

\section{REFERÊNCIAS BIBLIOGRÁFICAS}

ALMEIDA F.F.M. 1977. O Cráton do São Francisco. Revista Brasileira de Geociências, 7:349-364.

ALMEIDA V.V. 2009. Mineralogia e petrologia de xenólitos mantélicos da região de Ubatuba (SP) e Monte Carmelo $(M G)$ : evidências de fusão parcial e metassomatismo no manto superior do sudeste do Brasil. São Paulo, Dissertação de Mestrado, IGUSP, $112 \mathrm{p}$.

ANDRADE K.W. 2008. Geologia da Região Diamantifera do Rio Douradinho, ao sul de Coromandel-MG. Belo Horizonte, Monografia de Graduação, IGC-UFMG, 101p.

ANDRADE K.W. \& CHAVES M.L.S.C. 2009. Geologia e redistribuição sedimentar pós-cretácica dos depósitos diamantíferos da região ao sul de Coromandel (MG). Geonomos, $17: 27-36$. 
BARBOSA O. 1991. Diamante no Brasil: Histórico, Ocorrência, Prospecção e Lavra. Brasília, Ed. CPRM, 136p.

BARBOSA O., BRAUN O.P.G., DYER R.C., CUNHA C.A.B.R. 1970. Geologia da região do Triângulo Mineiro. Rio de Janeiro, DNPM/DPFM, Boletim 136, 140p.

BIZZI L.A., SMITH C.B., DE WIT M.J., ARMSTRONG R.A., MEYER H.O.A. 1991. Mesozoic kimberlites and related alkali rocks in the southwestern São Francisco Craton, Brazil: a case for local mantle reservoirs and their interaction. In: International Kimberlite Conference, 5, Proceedings of..., Araxá (Brazil), p.156-171.

CAMPOS J.E.G. \& DARDENNE M.A. 1997. Origem e evolução tectônica da Bacia Sanfranciscana. Revista Brasileira de Geociências, 27:283-294.

CARSON R.W., ARAÚJO A.L.N., JUNQUEIRA-BROD T.C., GASPAR J.C., BROD J.A., PETRINOVIC I.A., HOLLANDA M.H.B.M., PIMENTEL M.M., SICHEL S. 2007. Chemical and isotopic relationships between peridotite xenolhits and maficultrapotassic rocks from Southern Brazil. Chemical Geology, 242:415-434.

CARVALHO J.B. 1997. Petrologia de xenólitos mantélicos da Província Alto Paranaíba, Minas Gerais e Goiás. Brasília, Tese de Doutorado, IG-UnB, 239p.

CHAVES M.L.S.C. 1991. Seqüências cretácicas e mineralizações diamantíferas no Brasil Central: considerações preliminares. Geociências, 10:231-245.

CHAVES M.L.S.C., BENITEZ L, VEIGA B.N., MOREIRA L.A. 2005. Microdiamantes da bacia do Rio Douradinho (Coromandel, MG): morfologia primária e aspectos de dissolução. In: Simpósio Brasileiro de Geologia do Diamante, 4, Anais do..., Diamantina, p.39-42.

CHAVES M.L.S.C., BENITEZ L., CHAMBEL L. 2006. Análise comparativa dos aspectos superficiais de populações de diamantes nas províncias da Serra do Espinhaço e do Alto Paranaíba (MG). In: Congresso Brasileiro de Geologia, 43, Coletânea de Trabalhos Completos do..., Aracaju, p.807-811.

CHAVES M.L.S.C., BENITEZ L., BRANDÃO P.R.G., GIRODO A.C. 2008. Kimberlito Canastra-1 (São Roque de Minas, MG): geologia, mineralogia e reservas diamantíferas. REM-Revista da Escola de Minas, 61:357-364.

CHAVES M.L.S.C., ANDRADE K.W., MOREIRA L.A. 2009. A intrusão diamantífera Abel Régis: kimberlito ou lamproíto? Revista da Escola de Minas, 62:431-438.

DAVIS G.L. 1977. The ages and uranium content of zircons from kimberlites and associated rocks. In: International Kimberlite Conference, 2, Extended Abstracts of.., Santa Fe (New MexicoUSA), p.78-80.

GRÜTTER H.S., GURNEY J.J., MENZIES A.H., WINTER F. 2004. An update classification scheme for mantle-derived garnet for use by diamond explores. Lithos, 77:841-857.

HEINECK C.A., LEITE C.A.S., SILVA M.A., VIEIRA V.S. 2003. Mapa geológico do Estado de Minas Gerais, Escala 1:1.000.000. Belo Horizonte: Convênio COMIG/CPRM, 2003, 1 folha.

LADEIRA E., BRAUN O.P.G., CARDOSO R.N., HASUI Y. 1971. O Cretáceo em Minas Gerais. In: Congresso Brasileiro de Geologia, 25, Anais do..., São Paulo, p.15-31.

LEONARDOS O.H., CARVALHO J.B., GIBSON S.A., THOMPSON R.N. 1995. The diamond potential of the Late Cretaceous Alto Paranaiba igneous province, Brazil. In: International Kimberlite Conference, 6, Extended Abstracts of..., Novosibirsk (Russia), p. $320-322$.

MEYER H.O.A., GARWOOD B.L., SVISERO D.P. 1991. The Pântano intrusion. In: International Kimberlite Conference, 5, Field Guide Book of..., Araxá (Brazil), p.59-63.

MITCHELL R.H. 1986. Kimberlites - Mineralogy, Geochemistry, and Petrology. New York, Plenum Press, 442p.

PEREIRA R.S. 2007. Craton do São Francisco, kimberlitos e diamantes. Brasília, Tese de Doutorado, IG-UnB, 200p.

PIMENTEL M.M., RODRIGUES J.B., DELLAGIUSTINA M.E.S., JUNGES S., MATTEINI M., ARMSTRONG R. 2011. The tectonic evolution of the Neoproterozoic Brasilia Belt, central Brazil, based on SHRIMP and LA-ICPMS U-Pb sedimentary provenance área: a review. Journal of South American Earth Sciences, 31:345-357.
PIRES F.R.M. 1984. The southern limits of the São Francisco craton. Anais da Academia Brasileira de Ciências, 56:115-126.

READ G., GRUTTER H., WINTER S., LUCKMAN N., GAUNT F., THOMSEN F. 2004. Stratigraphic relations, kimberlite emplacement and lithospheric thermal evolution, Quiricó basin, Minas Gerais State, Brazil. Lithos, 77:803-818.

SEER H.J. 1999. Evolução Tectônica dos Grupos Araxá, Ibiá e Canastra na sinforma de Araxá, Minas Gerais. Brasília, Tese de Doutorado, IG-UnB, 267p.

SGARBI G.N.C., Sgarbi P.B.A, Campos J.E.G, Dardenne M.A, Penha U.C. 2001. Bacia Sanfranciscana: registro fanerozóico da Bacia do São Francisco. In: Pinto C.P. \& Martins-Neto M.A. Bacia do São Francisco; Geologia e Recursos Naturais. Belo Horizonte, Ed. SBG-MG, p.93-138.

SVISERO D.P., HARALYI N.L.E., GIRARDI V.A.V. 1980. Geologia dos kimberlitos Limeira 1, Limeira 2 e Indaiá, Douradoquara, MG. In: Congresso Brasileiro de Geologia, 31, Anais do..., Balneário de Camboriú, v.3, p.1789-1801.

SVISERO D.P., HARALYI N.L.E., FEITOSA V.M.N. 1982. Geologia e geofísica do kimberlito Sucuri, Monte Carmelo, Minas Gerais. In: Congresso Brasileiro de Geologia, 32, Anais do..., Salvador, v.2, p.465-474.

SVISERO D.P., MEYER H.O.A., HARALYI N.L.E., HASUI Y. 1984 A note on the geology of some Brazilian kimberlites. Journal of Geology, 92:331-338. 